\section{Driving CAR-based cellular therapies}

\section{By Tracey Baas, Senior Editor}

Adoptive T cell therapies were first developed in the mid-1980s but only recently entered the limelight owing to dramatic clinical results achieved with the latest incarnation, chimeric antigen receptor-based cell therapies. Novartis AG's 2012 chimeric antigen receptor deal with the University of Pennsylvania signaled the start of a land grab.

There are now at least 12 chimeric antigen receptors (CARs) in the clinic from multiple academic-industry collaborations, and companies are letting the researchers do the driving.

Remaining challenges with adoptive $\mathrm{T}$ cell therapies include optimizing antigen engagement without inducing off-target or on-target, off-tissue toxicities and enhancing $\mathrm{T}$ cell expansion and long-term persistence.

To overcome these challenges, researchers are piecing together different genetic

"CAR and TCR T cell
therapies are not mutually
exclusive and can be
positioned as complementary
options."
-Gwendolyn Binder-Scholl,
Adaptimmune Ltd.

immune system naturally avoids making high-affinity TCRs against self-proteins to preclude autoimmune reactions. ${ }^{3}$

Thus, second-generation TCRs used endogenous, tumor-targeting TCRs as a starting point followed by optimization for potency and cancer antigen affinity.

Researchers have also developed an alternative approach using CARs as the antigen-recognizing molecule. ${ }^{4}$ CARs are synthetic receptors consisting of heavy and light antibody chains fused to a $\mathrm{T}$ cell signaling molecule capable of activating the $\mathrm{T}$ cell response.

CARs can be designed to recognize tumor-associated protein, carbohydrate or glycolipid antigens presented in an MHC-independent manner on the outside of cells. This gives CAR-based T cell therapies the advantage of circumventing tumor immune evasion, which is often triggered by MHC-dependent T cell activity.

Because CARs can target antigen independently of MHC, only one CAR has to be designed for each tumor-associated antigen. Multiple TCRs need to be designed to target antigen presented by different patient-specific MHCs.

The main advantage of TCRs is that they can target any protein no matter where it is in the cell.

"CAR and TCR T cell therapies are not mutually exclusive and can be positioned as complementary options," said Gwendolyn Binder-Scholl, EVP of Adaptimmune Ltd.

\section{CAR talk}

First-generation CARs included only one T engineering and culturing procedures to build better T cells as well as assembling various preclinical screening strategies to assess toxicities. Current technologies to anticipate target antigen homologies are limited. Tools include gene and protein expression databases and panels of primary and 3D differentiated cell cultures representing organ tissues to identify possible off-target and on-target, off-tissue toxicities. ${ }^{1,2}$

In addition, clinicians are determining what types of preconditioning procedures for patients give the engineered T cells the best chance for proliferating in the patient and battling cancer.

\section{Building a better $\mathrm{T}$ cell}

The first generation of $\mathrm{T}$ cell-based approaches to targeting cancer cells relied on native $\mathrm{T}$ cell receptors (TCRs) that recognize tumorassociated antigens. Unlike mAb-based approaches, TCRs offered the benefits of active trafficking to tumor sites, in vivo expansion and long-term persistence.

TCRs consist of a heterodimer of $\alpha$ - and $\beta$-chains that recognizes processed antigenic peptides presented by major histocompatibility complex class I (MHC) molecules on the surface of a tumor cell. The targets can thus be antigens derived from intracellular or extracellular proteins as long as they are processed and displayed as MHC complexes.

Despite the clear selling points, the first generation of TCRs generally had low affinity and specificity for their targets because the cell-activating signaling molecule and showed limited antitumor effects owing to suboptimal T cell stimulation and proliferation. ${ }^{5}$

The real breakthroughs occurred with second-generation CARs, which consist of two $\mathrm{T}$ cell signaling molecules that provide enhanced activation of $\mathrm{T}$ cells and have better expansion, proliferation and persistence than first-generation CARs.

Research picked up speed when second-generation CARs were used to treat CD19+ leukemias and lymphomas.

In 2010, Steven Rosenberg's laboratory at the National Cancer Institute (NCI) provided the first clinical evidence that supported the potential of second-generation CARs. The team's CD19-specific CARs, which used the $\mathrm{T}$ cell signaling molecules $\mathrm{CD} 3 \zeta$ and $\mathrm{CD} 28$, produced a long-lasting, partial remission of lymphoma in a patient and regression in four other patients. ${ }^{6}$

Rosenberg is chief of surgery at the NCI and a professor of surgery at the Uniformed Services University of the Health Sciences and at The George Washington University School of Medicine \& Health Sciences.

A year later, the potential curative power of CARs was demonstrated. A University of Pennsylvania team led by Carl June showed that two out of three patients with advanced chronic lymphocytic leukemia (CLL) went into complete remission after receiving engineered $\mathrm{T}$ cells that contained second-generation CARs specific for CD19 fused to the signaling molecules tumor necrosis factor receptor superfamily member 9 (TNFRSF9; 4-1BB; CD137) and CD3 $\zeta^{7.8}$ 


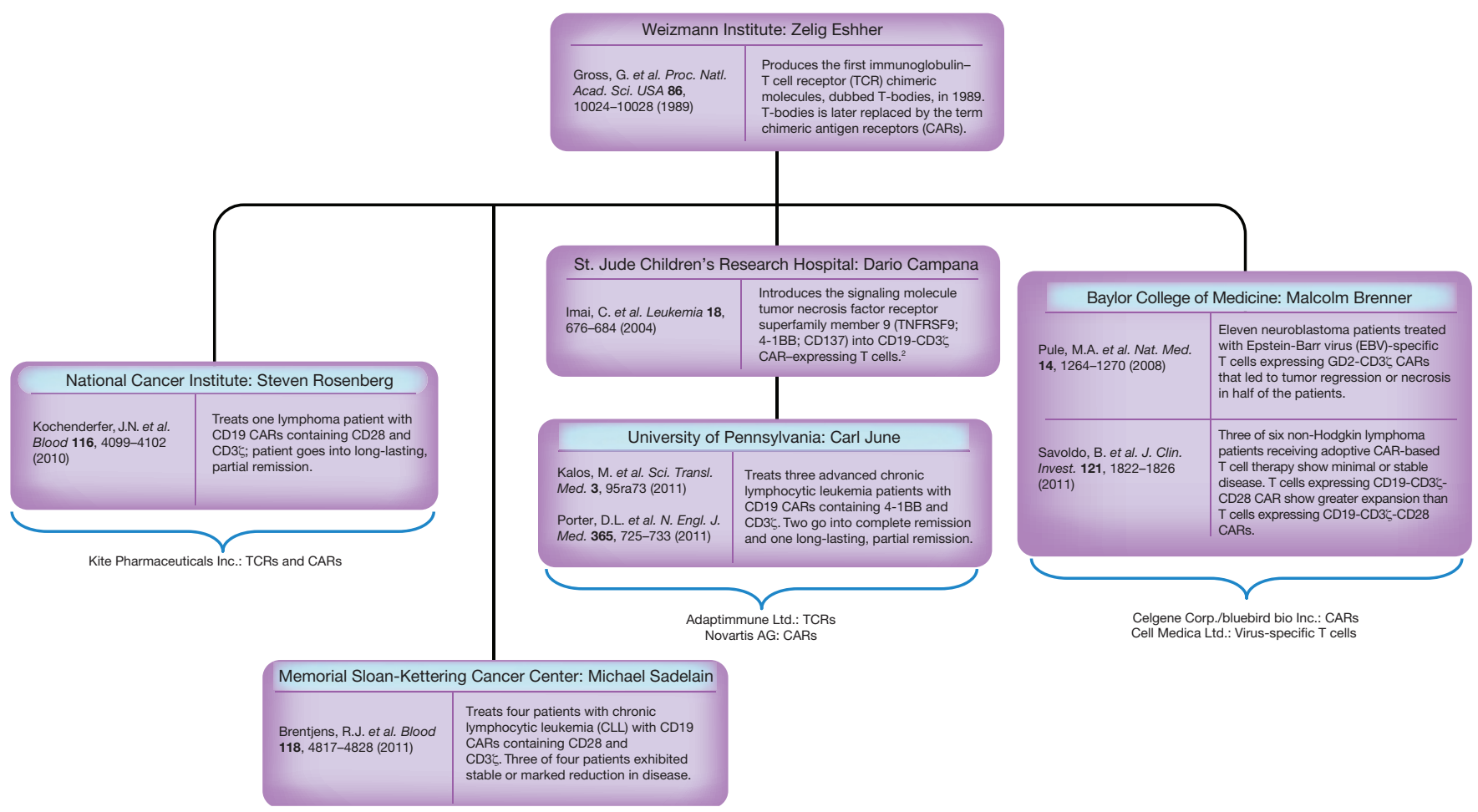

Figure 1. Preclinical and clinical studies that drove CAR-based T cell therapeutic development. About 20 years of cumulative work in academic centers has driven adoptive T cell therapies featuring chimeric antigen receptors (CARs) into the clinic and caught the attention of numerous biotechs and pharmas. Clinical studies are noted in blue.

June is a professor in the Department of Pathology and Laboratory Medicine at the Perelman School of Medicine at the University of Pennsylvania and director of the translational research program at the Abramson Family Cancer Research Institute at the University of Pennsylvania.

Within days of the UPenn report, Michel Sadelain's group at Memorial Sloan-Kettering Cancer Center (MSKCC) published a study showing that seven of eight patients with CLL and a patient with

"There had been about 20 years of work in T cell therapies, but it wasn't until there was concrete evidence for strong efficacy in patients that it became clear that the tide had turned."

-Charles Wilson, Novartis AG acute lymphoblastic leukemia (ALL) went into partial remission after receiving $\mathrm{T}$ cells expressing a CD19 CAR that also included the signaling molecules $\mathrm{CD} 3 \zeta$ and $\mathrm{CD} 28 .^{9}$

Sadelain is director of MSKCC's Center for Cell Engineering.

\section{Partnering up}

The 2 reports in 2011 caught the attention of industry (see Table 1, "Selected deals and partnerships in the adoptive $\mathrm{T}$ cell immunotherapeutic space from 2008 onward"). In August 2012, Novartis licensed rights to UPenn's therapy. The university received an undisclosed upfront payment and is eligible for milestones plus royalties.

The pharma also agreed to provide $\$ 20$ million to establish the Center for Advanced Cellular Therapies (CACT) at the university to co-develop
CAR-based therapies. ${ }^{10}$

"We had been tracking the space, but our interest in June's work solidified with the publication of his clinical trial results in The New England Journal of Medicine. ${ }^{8}$ There had been about 20 years of work in $\mathrm{T}$ cell therapies, but it wasn't until there was concrete evidence for strong efficacy in patients that it became clear that the tide had turned," said Charles Wilson, VP and global head of strategic alliances at Novartis (see Figure 1, "Preclinical and clinical studies that drove CAR-based T cell therapeutic development").

Bruce Levine, an associate professor in cancer gene therapy and director of the Clinical Cell and Vaccine Production Facility at UPenn, is outfitting the CACT and training Novartis personnel.

"Penn will conduct early phase clinical trials not only targeting CD19 but additional tumor targets in solid tumors. Novartis will conduct later phase and pivotal clinical trials at its Morris Plains facility, and then, following FDA approval, commercial production will take place at this facility as well," said Levine.

In addition, Novartis is assembling a toolbox of technologies needed to make the engineered T cells.

The pharma has an exclusive license from Life Technologies Corp. to use Dynabeads CD3/CD28 Cell Therapy Systems to isolate, activate and expand CAR-expressing T cells.

Under a May deal, Oxford BioMedica plc is using its LentiVector gene delivery technology to manufacture clinical-grade batches of Novartis' autologous T cells loaded with a lentiviral vector expressing a CD19 CAR linked to the immunostimulatory molecules CD3 $\zeta$ and 
Table 1. Selected deals and partnerships in the adoptive T cell immunotherapeutic space from 2008 onward. The August 2012 deal between Novartis AG and the University of Pennsylvania set off a wave of partnering activity in the chimeric antigen receptor (CAR)based T cell therapeutic space, but collaborations between gene therapy company Adaptimmune Ltd. and East Coast universities and between accelerator Celdara Medical LLC and the Geisel School of Medicine at Dartmouth College had already been flying under the radar for a couple of years. The University of Pennsylvania granted Novartis exclusive, worldwide rights to develop and commercialize CAR immunotherapies for cancer. Additionally, Novartis will provide \$20 million to establish the Center for Advanced Cellular Therapies on the university's campus to co-develop CAR-based therapies to treat cancer. In October 2012, Kite Pharma Inc. was granted exclusive access to the National Cancer Institute's ( $\mathrm{NCl}$ ) current and future engineered peripheral blood autologous T cell therapeutics to treat hematological and solid cancers. Kite has the option to an exclusive license for $\mathrm{NCl}$ proprietary products being developed under the Cooperative Research and Development Agreement. The company will also provide funding to the NCI. In December 2012, Cellectis S.A. signed a broad collaboration agreement with University College London to develop CAR-expressing allogeneic T cells using Cellectis' proprietary genome engineering technologies to manufacture the T cells. In March 2013, bluebird bio Inc. partnered with Celgene Corp. to discover, develop and commercialize CAR immunotherapies for cancer. The partners will also work with the Baylor College of Medicine to develop new and existing CAR immunotherapy products and programs. bluebird bio and Celgene declined to disclose details. bluebird received an undisclosed upfront payment and is eligible for up to $\$ 225$ million in option fees and milestones per product, plus royalties. bluebird bio will be responsible for R\&D through Phase I testing, after which Celgene has the option to license any products.

Source: BCIQ: BioCentury Online Intelligence; BioCentury Archives; http://www. clinicaltrials.gov/

\begin{tabular}{|c|c|c|c|c|c|}
\hline Company & Academic leaders & Receptor type & Tumor-associated antigens & Date & Clinical trials \\
\hline Adaptimmune & $\begin{array}{l}\text { University of Pennsylvania; University of } \\
\text { Maryland, Baltimore; Roswell Park Cancer } \\
\text { Institute; Washington University in St. Louis; } \\
\text { Yale School of Medicine; City of Hope; The } \\
\text { Children's Hospital of Philadelphia; NCI; } \\
\text { Memorial Sloan-Kettering Cancer Center } \\
\text { (MSKCC) }\end{array}$ & $\begin{array}{l}\text { T cell receptors } \\
\text { (TCRs) }\end{array}$ & $\begin{array}{l}\text { Cancer/testis antigen 1B } \\
\text { (CTAG1B; NY-ESO-1) and } \\
\text { CTAG2 (LAGE1; NY-ESO-2) }\end{array}$ & 2008 & Started \\
\hline Celdara Medical & Geisel School of Medicine at Dartmouth College & CARs & $\begin{array}{l}\text { Killer cell lectin-like receptor } \\
\text { subfamily K member } 1 \text { (KLRK1; } \\
\text { CD314; NKG2D) }\end{array}$ & 2010 & $\begin{array}{l}\text { Expected late } \\
2014\end{array}$ \\
\hline Cell Medica Ltd. & Baylor College of Medicine & TCRs & Not applicable ${ }^{\mathrm{A}}$ & 2010 & Started \\
\hline $\begin{array}{l}\text { Novartis (NYSE:NVS; } \\
\text { SIX:NOVN) }\end{array}$ & University of Pennsylvania & CARs & CD19 and mesothelin & 2012 & Started \\
\hline Kite Pharma & $\mathrm{NCI}$ & CAR or TCRs & $\begin{array}{l}\text { CD19, VEGF receptor } 2 \text { (KDR/ } \\
\text { Flk-1; VEGFR-2), mesothelin, } \\
\text { epidermal growth factor } \\
\text { receptor (EGFR), NY-ESO-1 and } \\
\text { carcinoembryonic antigen (CEA) }\end{array}$ & 2012 & Started \\
\hline Cellectis (Euronext:ALCLS) & University College London & CARs & CD19 & 2012 & $\begin{array}{l}\text { Expected late } \\
2014\end{array}$ \\
\hline $\begin{array}{l}\text { Celgene (NASDAQ:CELG); } \\
\text { bluebird bio } \\
\text { (NASDAQ:BLUE) }\end{array}$ & Baylor College of Medicine & CARs & $\begin{array}{l}\text { GD2, HER2 (EGFR2; ErbB2; neu) } \\
\text { and CD19 }\end{array}$ & 2013 & Started \\
\hline Not applicable & MSKCC $^{\mathrm{B}}$ & CARs & $\begin{array}{l}\text { CD19 and prostate-specific } \\
\text { membrane antigen (PSMA; } \\
\text { FOLH1; GCPII) }\end{array}$ & $\begin{array}{l}\text { Not } \\
\text { applicable }\end{array}$ & Started \\
\hline
\end{tabular}
FOLH1; GCPII)

AThe TCRs do not target a tumor-associated antigen but instead antigens specific for viruses that are expressed by malignant cells in Epstein-Barr virus (EBV)associated lymphoma and nasopharyngeal carcinoma. ${ }^{\mathrm{B}} \mathrm{MSKCC}$ has been able to conduct its own Phase I clinical trials at their Memorial Hospital using T cell

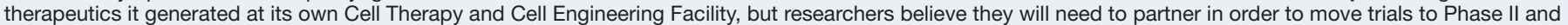
beyond.

4-1BB.

Kite Pharma Inc. was the next company to enter the space, by partnering with academia and government.

In October 2012, Kite announced the establishment of a partnership with the NCI Surgery Branch led by Rosenberg, under a Cooperative Research and Development Agreement (CRADA) for the development of autologous $\mathrm{T}$ cells engineered to express TCRs or CARs directed to multiple hematological and solid tumor types. Kite has the option to an exclusive license for NCI proprietary products being developed under the CRADA. Kite is focused on advancing this NCI clinical product pipeline into multicenter studies aimed at registration and commercialization.

Next on the scene was Celgene Corp., who took a distinct position and aligned itself with privately held biotechnology company bluebird bio Inc. and the Center for Cell and Gene Therapy at the Baylor College of Medicine, Texas Children's Hospital and Houston Methodist hospital. The Texas team is led by Malcolm Brenner, a professor of molecular and human genetics and the director for the Center for Cell and Gene Therapy at Baylor. Celgene believes that this collaboration is uniquely positioned to advance innovative approaches to provide treatment options for patients with intractable problems in oncology.

Celgene has an option to license any products resulting from the collaboration after the completion of Phase I trials. bluebird is responsible through Phase I studies.

bluebird received an undisclosed upfront payment and is eligible for up to $\$ 225$ million in option fees and milestones per product, plus 
royalties. The company has an option for 50/50 co-development and profit-sharing rights in the U.S.

The deal combines Celgene's cancer drug development capabilities with Baylor's CAR T cell immunotherapy expertise and bluebird's experience using lentiviral vectors to deliver genes into target cells taken from a patient's body.

The collaborators will work on CARs for liquid cancers as well as solid tumors. Tumor-associated antigens of primary interest to the partners include GD2, HER2 (EGFR2; ErbB2; neu) and CD19.

In the TCR space, Baylor College of Medicine has a deal with Cell Medica Ltd., which in-licensed T cell isolation technology in 2010. Baylor and Cell Medica are running a 40-patient, open-label Phase II trial of Cytorex EBV, an autologous cell therapy involving Epstein-Barr virus (EBV)-specific cytotoxic T cells for lymphoma and nasopharyngeal carcinoma.

"Our first efforts are to develop cell therapeutics with Baylor which use TCRs that are specific for viruses associated with cancer. For these cells we don't need genetic engineering steps because the T cells are targeting virus antigens expressed by the malignant cells and not a variation of self. We can use the naturally occurring sequences from TCRs produced by the body in response to viral infection," said Cell Medica CEO Gregg Sando.

"We also have second efforts already underway that focus on developing $\mathrm{T}$ cells that will be re-engineered to express TCRs for tumor antigens, such as Wilms tumor 1. We're not interested in going after CD19 with CARs since that area is saturated, but we're open to other targets," added Sando.

Other CAR deals include a partnership between the Geisel School of Medicine at Dartmouth College and Celdara Medical LLC, which is headquartered in the Dartmouth Regional Technology Center, which is a private, not-for-profit technology incubator.

The partners are developing autologous and allogeneic CAR T cells based on killer cell lectin-like receptor subfamily K member 1 (KLRK1; CD314; NKG2D), which is an NK cell receptor. NKG2D recognizes several ligands that are found on the tumors of about $90 \%$ of patients with cancer. It has shown efficacy and immune system engagement in multiple murine models of both solid and liquid tumors.

By April 2014, the partners plan to start enrolling patients with cancer in a Phase I trial to determine maximum tolerated dose and gain insight into mechanism of action.

In December 2012, University College London and Cellectis S.A. partnered to develop CARs and 7 months later reported that their allogeneic, CD19-specific, CAR-based T cells were curative in mice with human leukemia cells.

The lone unpartnered academic player with a significant presence in the CAR space is MSKCC.

"We were hoping to get into a situation like UPenn, but maybe we should have been more aggressive in contacting people," said Renier Brentjens, a medical oncologist at MSKCC. "We're finishing up Phase I trials, but to continue to further clinical trials we're going to need help from industry."

MSKCC is composed of Memorial Hospital, the world's largest cancer hospital, and Sloan-Kettering Institute. MSKCC has also created its own Cell Therapy and Cell Engineering Facility that meets FDA's GMP requirements. The facility is undergoing upgrades and is being expanded to 6,000 square feet.

CAR-based T cells are designed and preclinically tested at SloanKettering Institute. T lymphocytes can be collected from and re-infused into patients at Memorial Hospital, where patients also can receive preconditioning regimens prior to re-infusion and supportive care after the procedure.

The therapeutic T cells can be engineered directly at the Cell Therapy and Cell Engineering Facility.

"Because the center is at our fingertips, I think this gives us an edge. During the trials, we have a nice situation for fine-tuning our approach," said Brentjens. "Academic centers have a huge asset over facilities at biotech companies because we are often associated with hospitals and have room to be more innovative."

Baas, T. SciBX 6(41); doi:10.1038/scibx.2013.1152

Published online Oct. 24, 2013

\section{REFERENCES}

1. Cameron, B.J. et al. Sci. Transl. Med. 5, 197 ra103 (2013)

2. Baas, T. SciBX 6(33); doi:10.1038/scibx.2013.879

3. Restifo, N.P. et al. Nat. Rev. Immunol. 12, 269-281 (2012)

4. Dotti, G. et al. Hum. Gene Ther. 20, 1229-1239 (2009)

5. Curran, K.J. et al. J. Gene Med. 14, 405-415 (2012)

6. Kochenderfer, J.N. et al. Blood 116, 4099-4102 (2010)

7. Kalos, M. et al. Sci. Transl. Med. 3, 95ra73 (2011)

8. Porter, D.L. et al. N. Engl. J. Med. 365, 725-733 (2011)

9. Brentjens, R.J. et al. Blood 118, 4817-4828 (2011)

10. McCallister, E. BioCentury 20(33), A7-A8; Aug. 13, 2012

\section{COMPANIES AND INSTITUTIONS MENTIONED}

Abramson Family Cancer Research Institute at the University of Pennsylvania, Philadelphia, Pa.

Adaptimmune Ltd., Abingdon, U.K.

Baylor College of Medicine, Houston, Texas

bluebird bio Inc. (NASDAQ:BLUE), Cambridge, Mass.

Celdara Medical LLC, Lebanon, N.H.

Celgene Corp. (NASDAQ:CELG), Summit, N.J.

Cellectis S.A. (Euronext:ALCLS), Paris, France

Cell Medica Ltd., London, U.K.

Dartmouth Regional Technology Center, Lebanon, N.H.

Geisel School of Medicine at Dartmouth College, Hanover, N.H. The George Washington University School of Medicine \& Health Sciences, Washington, D.C.

Houston Methodist, Houston, Texas

Kite Pharma Inc., Los Angeles, Calif.

Life Technologies Corp. (NASDAQ:LIFE), Carlsbad, Calif.

Memorial Hospital, New York, N.Y.

Memorial Sloan-Kettering Cancer Center, New York, N.Y.

National Cancer Institute, Bethesda, Md.

Novartis AG (NYSE:NVS; SIX:NOVN), Basel, Switzerland

Oxford BioMedica plc (LSE:OXB), Oxford, U.K.

Perelman School of Medicine at the University of Pennsylvania,

Philadelphia, $\mathrm{Pa}$.

Sloan-Kettering Institute, New York, N.Y.

Texas Children's Hospital, Houston, Texas

Uniformed Services University of the Health Sciences,

Washington, D.C.

University College London, London, U.K.

University of Pennsylvania, Philadelphia, Pa. 